\title{
URBAN BUILT-UP AREA EXTRACTION AND APPLICATION BASED ON GF-2 SATELLITE DATA
}

\author{
Chang Xiao, Xiaomin $\mathrm{Yu}^{*}$ \\ Hubei Geomatics Information Center, Wuhan, China - (23132638, 37952574)@qq.com
}

Commission VI, WG III/1

KEY WORDS: GF-2 satellite, object-oriented method, built-up area, Shennongjia

\begin{abstract}
:
GF-2 satellite was launched in China on August 19, 2014. It has wide potential applications with the spatial resolution of around 1 meter. In this paper, urban built-up area was extracted and classified based on GF-2 satellite data using object-oriented method. Songbai town of Shennongjia forest region was taken as an example. The results were applied to urban-rural planning and supervision of Songbai town in Shennongjia forest region.
\end{abstract}

\section{INTRODUCTION}

GF-2 satellite was launched in China Taiyuan satellite launch center on August 19, 2014. It has the highest spatial resolution among optical earth observation satellites in China with the pan image spatial resolution of around 1 meter and the multispectral image spatial resolution around 4 meters. It also has the advantages of high radiation accuracy, high positioning accuracy and fast attitude maneuver capability and so on. GF-2 satellite can provide service support for industry applications like land use dynamic monitoring, mineral resources survey, urban and rural planning and evaluation, transportation network planning, forest resources survey, and desertification monitoring etc. Therefore, it is of great significance to carry out the research on information extraction method and application for GF-2 satellite image.

In this paper, the study on extraction and application of urban built-up area was carried out, based on GF-2 satellite images using GEOBIA method, taking Songbai town of Shennongjia forest region as an example. The first national geographic census data of Songbai town in 2015 was used as a thematic layer to carry out the multi-scale segmentation. Then the object oriented classification method was used to realize the extraction of urban built-up area, by optimizing the characteristics of the sample object.

\section{IMAGE DATA}

The test data used in this paper was the pan image and the multi-spectral image of GF-2 satellite acquired on March 28, 2016, covering Songbai town of Shennongjia forest region in Hubei province, China. It was provided by Hubei data and application center of high resolution earth observation system. The images are shown in Fig. 1.

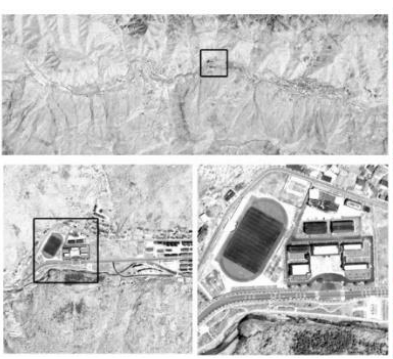

(a)

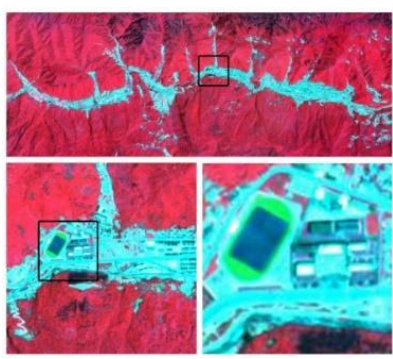

(b)
Fig.1. (a) pan image; (b) multi-spectral image

The selected band parameters of GF-2 satellite are shown in Tab.1.

Tab.1. Band parameters of GF-2 satellite

\begin{tabular}{|l|l|l|}
\hline Camera & Spectral range $/ \mu \mathrm{m}$ & Resolution $/ \mathrm{m}$ \\
\hline PAN & $0.45 \sim 0.90$ & \multirow{2}{*}{1} \\
\hline MSS1 & $0.45 \sim 0.52$ & \multirow{2}{*}{4} \\
\cline { 1 - 2 } MSS2 & $0.52 \sim 0.59$ & \\
\hline MSS3 & $0.60 \sim 0.69$ & \\
\hline MSS4 & $0.77 \sim 0.89$ &
\end{tabular}

\section{METHODS}

\subsection{Data Preprocessing}

Remote sensing image pre-processing usually includes orthorectification, image registration, and image fusion. These steps would help us extract terrain information better. Orthorectification can eliminate the image distortion caused by inclination of satellite camera, topographic relief, and surface features. DEM with 5 meter spatial resolution was used in the paper for the ortho-rectification of pan image and multi-spectral image. Image registration can eliminate the geometric deviation of the same point in the two images laying the important basis of image fusion. The two test images after geometric correction

\footnotetext{
* Corresponding author
} 
were coregistered to each other with an RMS error less than 0.5 pixels. Image fusion was to obtain a new image with rich colour information and high spatial resolution by transformation of pan image and multi-spectral image. There are many image fusion methods. PCA method was used in this paper. The fused new image was shown in Fig.2.

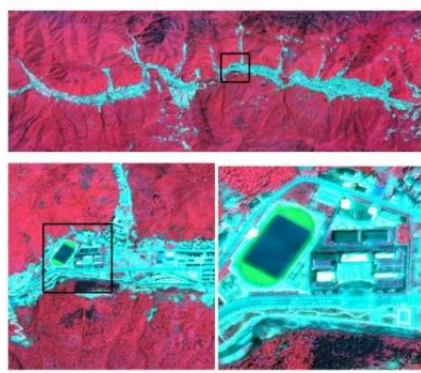

Fig.2. new image fused by PCA

\subsection{Object-oriented Classification}

Traditional pixel classification was based on the processing and analysis of pixel spectral features, without fully utilizing other information of the remote sensing images, such as geometric information, texture information, structure information, topological relations and so on. As a result, a large redundancy of spatial data comes to being without sufficient exertion of remote sensing advantage, which has resulted in a waste of resources. Therefore, for a more rational use of various features and auxiliary information of classification, object-oriented classification was used in the paper. Namely, the basic unit of image is no longer the individual pixel but a meaningful target with abundant spatial, textural and neighbouring features. This approach can extract the land cover types by analysing and processing the features of remote sensing images.

On the basis of the conventional multi-scale segmentation method, this paper used the first national geographic census data to assist the segmentation. It would improve the accuracy of urban built-up area extraction. The segmentation scale used in the paper was 50. The spectral and shape heterogeneity weights were 0.9 and 0.1 respectively. Then, the object oriented classification method was used to realize the extraction of urban built-up area, by optimizing the characteristics of the sample object. There were four representative features used for classification, such as Vegetation index, Soil brightness index, Asymmetry and Elongation index.

Tab.2. Feature information extraction

\begin{tabular}{|l|l|l|}
\hline $\begin{array}{l}\text { Feature } \\
\text { Type }\end{array}$ & Feature Name & $\begin{array}{l}\text { Calculation } \\
\text { Formula }\end{array}$ \\
\hline \multirow{2}{*}{$\begin{array}{l}\text { Spectral } \\
\text { Feature }\end{array}$} & $\begin{array}{l}\text { Normalized Difference } \\
\text { Vegetation Index }\end{array}$ & $(\mathrm{NIR}-\mathrm{R}) /(\mathrm{NIR}+\mathrm{R})$ \\
\cline { 2 - 3 } & Soil Brightness Index & $(\mathrm{B}-\mathrm{G}) /(\mathrm{B}+\mathrm{G})$ \\
\hline \multirow{2}{*}{$\begin{array}{l}\text { Geometric } \\
\text { Feature }\end{array}$} & Asymmetry & $1-\mathrm{v} / \mathrm{w}$ \\
\cline { 2 - 3 } & Elongation Index & area /length ${ }^{2}$ \\
\hline
\end{tabular}

Note: NIR is near-infrared; $R$ is red; $B$ is blue; $G$ is green, $v$ and $\mathrm{w}$ represent the long axis and the short axis, respectively.

\section{RESLUTS AND APPLICATION}

Urban built-up area of Songbai town in Shennongjia forest region extracted and classified by object-oriented method was shown in Fig.3.

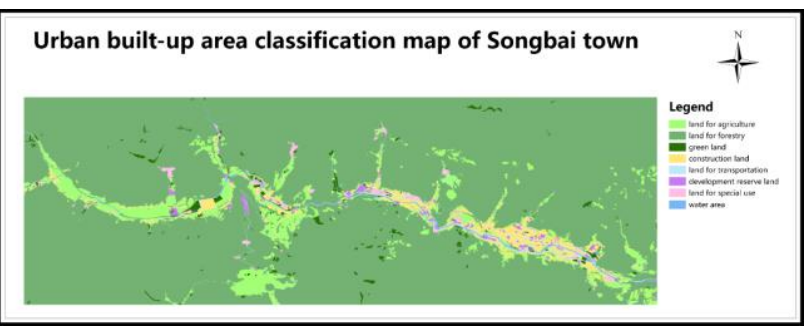

Fig.3. Urban built-up area classification map of Songbai town

The overlay analysis of urban built-up area extracted from GF-2 satellite images and urban-rural planning data can help us find out the illegal construction land. So it will be able to provide decision support for preparation, implementation, supervision and revision of the urban-rural planning, supplemented by field check. Urban-rural planning data used in the paper was shown in Fig.4.

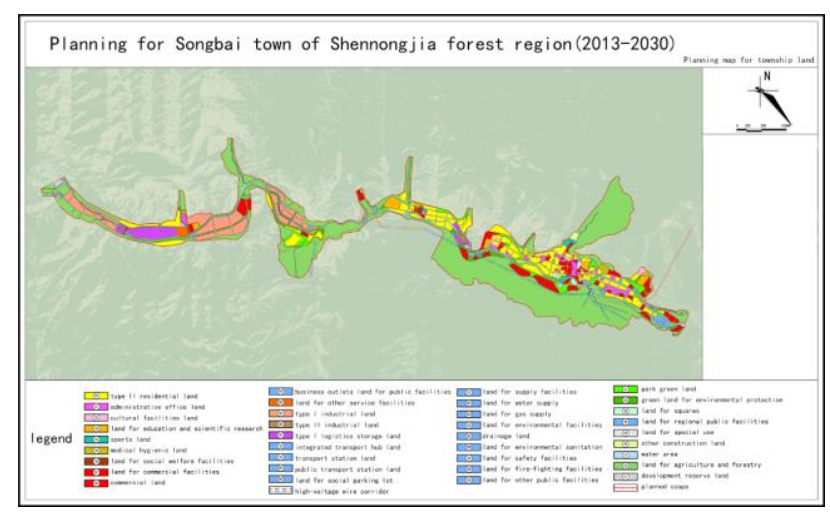

Fig.4. Urban-rural planning map of Songbai town

By overlay analysis, we found out that illegal construction outside the range of overall city planning is very common. In Fig.5 (a) and (b), the agricultural and forestry land in the urban master plan turned out to be a construction land in classification result. In Fig.5 (c), construction land in classification result not only occupies a planned land for agriculture and forestry, but also goes beyond the scope of the overall urban planning. These examples are not allowed according to urban and rural planning law of China.

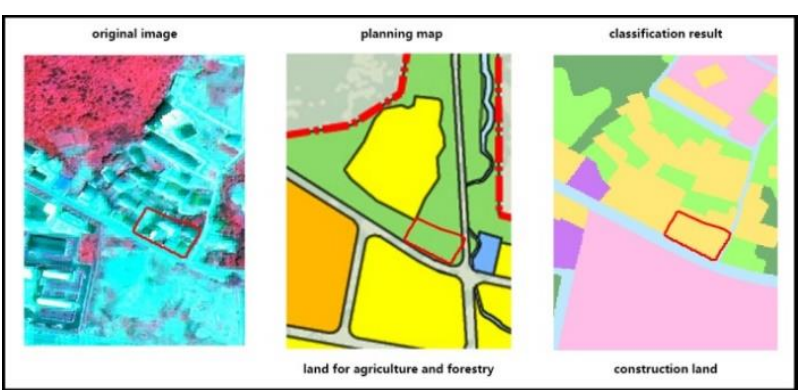

(a) 


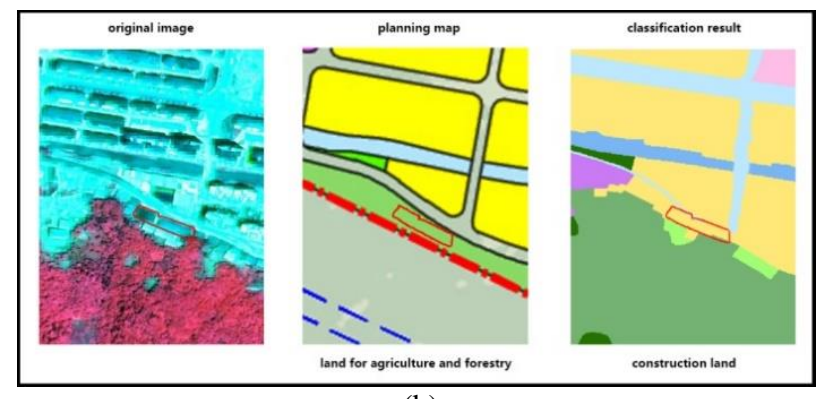

(b)

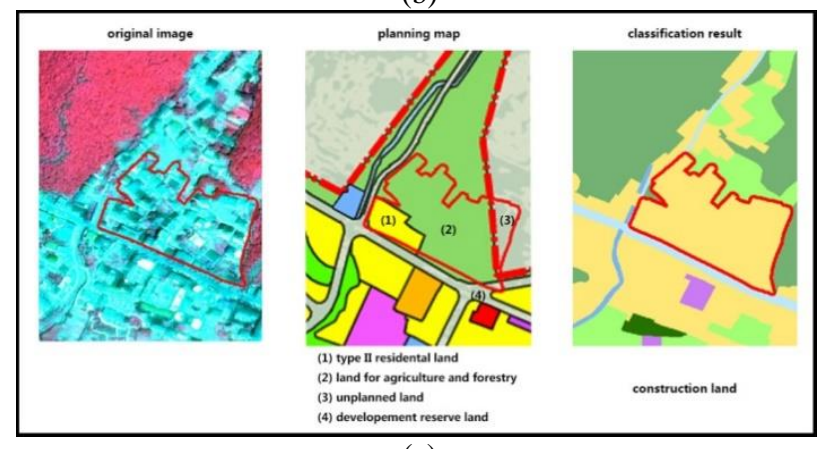

(c)

Fig.5. overlay analysis results

\section{CONCLUSION REMARKS}

In this paper, urban built-up area was first extracted and classified by object-oriented method, and then applied to urbanrural planning and supervision based on GF-2 satellite images, taking Shennongjia forest region research area. The results show that the object-oriented classification method is very suitable for the information extraction from GF-2 satellite images, which can obtain high accuracy results. And GF-2 satellite images can provide better data support for the application of urban planning.

\section{ACKNOWLEDGEMENTS}

This study was partially supported by The National Key Technology Support Program of China under grant 2015BAJ05B01.

\section{REFERENCES}

D.F. Xiong, "Image Fusion Analysis of the Second Highrescolution satellite," [J]. GEOMATICS\&SPATIAL INFORMATION TECHNOLOGY, 2016, 39(9): 102-108.

H. REN, "Object-oriented Surface Coverage Extract Methods of Geographic Situation Census," [J]. GEOSPATIAL INFORMATION, 2014, 12(3):14-16.

L.L. Liu, "Monitoring of urban ecological land research based on GF-1 image," [D]. China University of Geosciences master degree Thesis, 2015.

W.F. Fan, H.Z. Li, Q. Wen, X.M. Gao, "Research on Accuracy of Digital Ortho Rectification of GF-2 Image," [J]. BULLETIN of SURVEYING and MAPPING, 2016(9): 63-66.

X.J. Wu, C.C. Xiao, Z.Y. Cui, and X.J. Liu, "Coastline Extraction based on Object-oriented Method Using GF-2 Satellite data," [J]. SPACECRAFT RECOVERY\&REMOTE SENSING, 2015, 36(4):84-92.
X.M. Yu, B. Li, J. Shao, J.J. Zhou, "Land cover change detection of Ezhou huarong district based on multi-temporal ZY-3 satellite images," [C]. The 23th International Conference on Geoinformatics (Geoinformatics 2015), 19-21 June, 2015 in Wuhan, China.

X.M. YU, "Study on Key Technology of Object-oriented Image Classification," [D]. Beijing Normal University master degree thesis, 2007.

Z.W. Wang, S.X. Liu, J.W. Dai, S.C. You, "Registration Strategy for GF-2 Satellite Multispectral and Panchromatic Images," [J]. SPACECRAFT RECOVERY\&REMOTE SENSING, 2015, 36(4):48-53.

Revised March 2018 